\title{
The Effect of Acute Tryptophan Depletion on the Neural Correlates of Emotional Processing in Healthy Volunteers
}

\author{
Jonathan P Roiser*, 1,2, Jamey Levy², Stephen J Fromm², Hongye Wang ${ }^{2}$, Gregor Hasler², Barbara J Sahakian ${ }^{3}$ \\ and Wayne $C$ Drevets ${ }^{2}$
}

'Department of Imaging Neuroscience, Institute of Neurology, London, UK; ${ }^{2}$ Section on Neuroimaging in Mood and Anxiety Disorders, National Institute of Mental Health, National Institutes of Health, Bethesda, MD, USA; ${ }^{3}$ Department of Psychiatry, Addenbrooke's Hospital, University of Cambridge, Cambridge, UK

\begin{abstract}
The processing of affective material is known to be modulated by serotonin (5-HT), but few studies have used neurophysiological measures to characterize the effect of changes in 5-HT on neural responses to emotional stimuli. We used functional magnetic resonance imaging to investigate the effect of acute tryptophan depletion, which reduces central 5-HT synthesis, on neural responses to emotionally valenced verbal stimuli. Though no participants experienced significant mood change, emotional information processing was substantially modified following 5-HT depletion. A behavioral bias toward positive stimuli was attenuated following depletion, which was accompanied by increased hemodynamic responses during the processing of emotional words in several subcortical structures. Inter-individual differences in tryptophan depletion-elicited anxiety correlated positively with the caudate bias toward negative stimuli. These data suggest that 5-HT may play an important role in mediating automatic negative attentional biases in major depression, as well as resilience against negative distracting stimuli in never-depressed individuals.

Neuropsychopharmacology (2008) 33, 1992-2006; doi: I0.1038/sj.npp. I30158I; published online 19 September 2007
\end{abstract}

Keywords: serotonin; acute tryptophan depletion; functional magnetic resonance imaging; emotion; affective go/no-go test; caudate

\section{INTRODUCTION}

The central serotonergic system plays a major role in the regulation of emotional behavior, and is strongly implicated in the pathophysiology of major depression (Schatzberg et al, 2002). However, the neurobiological mechanisms by which serotonin (5-HT) affects emotional processing remain poorly understood. Here, we used acute tryptophan depletion (ATD) in order to study the effects of a temporary reduction in 5-HT synthesis on behavioral and neural responses to emotional stimuli in healthy volunteers, using functional magnetic resonance imaging (fMRI).

ATD has proved an instructive paradigm in studying how 5-HT modulates mood, emotional processing, and cognition in both patient populations and healthy volunteers (Bell et al, 2005). ATD has been used for over two decades as an experimental tool to cause a temporary and reversible reduction in 5-HT synthesis in humans and experimental animals. This reduction is achieved by selectively excluding the essential amino acid tryptophan, the precursor to 5-HT,

*Correspondence: Dr JP Roiser, Department of Imaging Neuroscience, Institute of Neurology, Room 807, Queen Square House, London WCIN 3BG, UK, Tel: + 44207837361 I x427I, Fax: + 44207676 205।,E-mail: j.roiser@ion.ucl.ac.uk

Received 24 May 2007; revised 16 August 2007; accepted 17 August 2007 from the diet (Young et al, 1985). The most well-known effect of ATD is to produce a temporary recurrence of some depressive symptoms in a proportion of patients who have previously experienced a major depressive episode but who are euthymic at the time of testing (Booij et al, 2002). This effect appears to be most marked in patients maintained on selective serotonin reuptake inhibitors (SSRIs), though mood change in unmedicated remitted major depressive disorder patients has also been reported (Neumeister et al, 2004).

Typically, ATD does not result in mood change in volunteers without a history of affective illness. Nevertheless, many studies have reported that ATD impairs performance on neuropsychological tasks that have an emotional component in healthy humans. For example, it has been reported that ATD impaired decision-making on gambling games (Rogers et al, 1999, 2003), attenuated motivation on a reinforced speeded reaction-time task (Cools et al, 2005a; Roiser et al, 2006), impaired recognition of emotional expressions (Harmer et al, 2003), and resulted in a negative bias on an emotional inhibitory control paradigm, the affective go/no-go test (AGNG) (Murphy et al, 2002). Interestingly, such a negative bias on the AGNG has also been found in depressed patients studied under basal conditions (ie without manipulation of serotonergic function: Erickson et al, 2005; Murphy et al, 1999). A followup study using fMRI suggested that in depressed individuals 
this bias was mediated by altered activity in the ventral anterior cingulate cortex (ACC) and other ventromedial prefrontal and subcortical structures (Elliott et al, 2002). These medial prefrontal cortical areas form part of a 'visceromotor' network, which participates in modulating the behavioral and visceral responses to emotional stimuli (Ongur and Price, 2000); notably, the same areas have consistently been implicated in the pathophysiology of depression (Drevets, 2000).

Emerging evidence suggests that even in individuals who do not experience mood change following perturbation of the 5-HT system, changes to the neural processing of emotional information still occur, particularly in the visceromotor network and connected subcortical structures. In one recent study, healthy volunteers administered the SSRI citalopram (to acutely elevate intrasynaptic 5-HT concentrations) showed reduced hemodynamic responses in the amygdala to threat-related facial expressions (Harmer et al, 2006). Complementing this finding, other studies demonstrated that decreasing serotonergic function via ATD increased hemodynamic responses in the amygdala to threat-related facial expressions in vulnerable individuals (Cools et al, 2005b; van der Veen et al, 2007).

However, no published study to date has investigated the effect of ATD on emotionally valenced verbal stimuli. Understanding how dysfunctional 5-HT transmission might alter the neural processing of emotional stimuli is an important step in integrating neurochemical and neuroanatomical explanations of MDD. Furthermore, since healthy volunteers show a bias toward positive words in attentional tasks (Erickson et al, 2005), such an understanding may shed light on the neural mechanisms underlying resilience to negative stimuli in never-depressed healthy individuals.

Therefore, in the present study we aimed to characterize the effect of a temporary reduction in 5-HT availability on neural and behavioral responses to emotionally valenced verbal stimuli, using the AGNG, in healthy volunteers. We predicted that ATD would lead to a negative emotional bias on the AGNG, and hypothesized that this bias would be mediated by altered activity in the orbital and medial prefrontal cortex (PFC) regions implicated in processing the emotional salience of sensory stimuli and in organizing behavioral and visceromotor responses to such stimuli, together with anatomically related areas of the ventral striatum, thalamus, cingulate gyrus, and temporal lobe (amygdala, hippocampus, parahippocampal cortex, and superior and middle temporal gyri) (Kondo et al, 2005; Ongur et al, 2003; Ongur and Price, 2000).

\section{MATERIALS AND METHODS}

\section{Participants}

Right-handed healthy volunteers between 18 and 50 years of age were recruited by newspaper advertisement in the Washington, DC metropolitan area. Volunteers were screened for medical and psychiatric disorders by medical history, physical examination, laboratory testing (including drug screening), neuromorphological magnetic resonance imaging (MRI) scanning, electrocardiogram, the Structured Clinical Interview for DSM-IV (SCID; Spitzer et al, 2002), and a semi-structured interview with a psychiatrist. The
Family Interview for Genetic Studies (Maxwell, 1992) was used to screen for family history of psychiatric disorders. Volunteers were excluded from participation if they had: (1) current or past psychiatric disorders (DSM-IV criteria); (2) first-degree relatives with mood or anxiety disorders; (3) major medical or neurological disorders; (4) exposure to psychotropic drugs or other medications likely to affect cerebral physiology, vascular function or anatomy within 3 weeks, or illicit drugs within 1 year; (5) alcohol abuse within 1 year or lifetime history of alcohol or drug dependence (DSM-IV criteria); (6) tobacco use within 3 months; (7) current pregnancy or breast feeding; (8) general MRI exclusions. For female participants, the menstrual phase was determined by home urine ovulation kits to detect the mid-cycle lutenizing hormone surge (Clear Plan Easy; Whitehall Laboratories; Madison, NJ, USA), and testing in the week prior to menstruation or during the first 4 days of menses was avoided. All participants provided informed consent following a full explanation of the procedures and purpose of the study, as approved by the National Institute of Mental Health Institutional Review Board.

\section{Experimental Procedure}

Participants attended two amino acid challenge sessions, separated by at least 1 week, in a double-blind placebocontrolled, crossover design. Participants fasted for at least $8 \mathrm{~h}$ prior to the challenge. On the tryptophan depletion day (TRP-) participants were administered 70 white capsules containing L-isoleucine $(4.2 \mathrm{~g})$, L-leucine $(6.6 \mathrm{~g})$, L-lysine (4.8 g), L-methionine (1.5 g), L-phenylalanine (6.6 g), Lthreonine $(3.0 \mathrm{~g})$, and $\mathrm{L}$-valine $(4.8 \mathrm{~g})$, and 4 pink capsules containing lactose (1.2 g) (total amino acid load: $31.5 \mathrm{~g}$ ). On the sham depletion day (TRP + ) the amino acid mixture in the 70 white capsules was the same, but the pink capsules contained L-tryptophan (1.2 g) (total amino acid load $32.7 \mathrm{~g}$, $3.67 \%$ L-tryptophan). Both researchers and participants were blind as to the identity of the pink capsules, which were prepared by a pharmacist who was not involved in any other experimental procedure.

A $15 \mathrm{ml}$ blood sample was obtained via an indwelling intravenous cannula immediately preceding amino acid ingestion to determine baseline $\left(\mathrm{T}_{0}\right)$ plasma tryptophan and other large neutral amino acid (LNAA) concentrations. Baseline mood ratings (Hamilton Depression Rating Scale (HAM-D: Hamilton, 1960), Hamilton Anxiety Rating Scale (HAM-A: Hamilton, 1959), State-Trait Anxiety Inventory (STAI: Spielberger et al, 1970), Profile of Mood States (POMS: McNair et al, 1971) and Automatic Thoughts Questionnaire (ATQ: Hollon and Kendall, 1980)), and vital signs (pulse and blood pressure) were also obtained.

For the next $5 \mathrm{~h}$, participants rested on the ward, and either watched television, read or slept. Participants continued to fast, but were allowed to drink water. Between 4.5 and $5 \mathrm{~h}$ following amino acid ingestion $\left(\mathrm{T}_{5}\right)$, a second blood sample was obtained and vital signs and mood measures were repeated. Participants then underwent an MRI scan lasting 60-90 min, including a high-resolution T1-weighted structural sequence and three echo-planar imaging (EPI) sequences, during which participants performed the AGNG. Details of all scanning procedures 
and the cognitive activation paradigm are provided below.

Following the MRI scan, participants returned to the ward for a final $\left(\mathrm{T}_{7}\right)$ blood sample and mood assessment. Participants were then provided with a protein-rich meal of their choice and returned home. Participants were contacted the day after each challenge to inquire whether they had experienced any persistent mood change.

\section{Cognitive Activation Paradigm (Affective Go/No-Go Test)}

Participants performed the AGNG during fMRI on each study day. The AGNG used the same conditions, stimuli, and stimulus timings as described for the task of Elliott $e t$ al $(2000,2002)$, but was modified slightly by splitting the task into three separate runs. Briefly, in each block words of two different emotional valences (either positive, negative or neutral) were presented quickly in the middle of the screen, one after the other, in a random sequence. A total of 10 words of each valence were presented, each remaining on the screen for $300 \mathrm{~ms}$, with a $900 \mathrm{~ms}$ gap between each word. Immediately before each block, participants read instructions on-screen for $6 \mathrm{~s}$, which informed them that should respond to each word of a particular valence (the target valence) and not respond to each word of the other valence (the distractor valence). Participants responded using a button-box in the scanner, and each button press was recorded. A 1200 ms gap was inserted immediately after the offset of the instructions, prior to the onset of the first word in each block to ensure that participants were able to read the first word. Each block therefore lasted $25.2 \mathrm{~s}$, with a rest period (18 s fixation cross followed by $6 \mathrm{~s}$ of instructions) preceding each block.

Words of each emotional valence could either be the targets or the distractors, creating six conditions: (1) happy targets, sad distractors; (2) happy targets, neutral distractors; (3) sad targets, happy distractors; (4) sad targets, neutral distractors; (5) neutral targets, happy distractors; (6) neutral targets, sad distractors. Two control conditions were also included, which contained only neutral words, where the target and distractor words were presented in different fonts (italic or normal): (7) neutral words in normal font targets, neutral words in italic font distractors; (8) neutral words in italic font targets, neutral words in normal font distractors. Participants performed three runs of the test, each lasting just under $7 \mathrm{~min}$, in which all eight conditions were presented once, in a pseudo-random order. A different order was used for each participant on each challenge day. Between each run participants rested for approximately $3 \mathrm{~min}$.

\section{MRI Scanning}

Participants were scanned during task performance using a 3T scanner (GE Signa, Milwaukee, WI). A total of 208 functional blood oxygenation-level dependent (BOLD) MRI images were acquired using an EPI pulse sequence (38 contiguous slices, $\mathrm{TE}=23 \mathrm{~ms}$; $\mathrm{TR}=2000 \mathrm{~ms}$; flip angle $=90^{\circ}$; field of view $=22 \mathrm{~cm}$; $64 \times 64$ matrix; voxel dimensions $=3.5 \times 3.44 \times 3.44 \mathrm{~mm}^{3}$ ). The first four images from each run were discarded to account for $\mathrm{T} 1$ equilibration. A high-resolution anatomical scan (spoiled gradient recalled-SPGR) was also acquired for every participant.

\section{Biochemical Measures}

Plasma was separated by centrifugation and stored at $-20^{\circ} \mathrm{C}$. Plasma total amino acid concentrations (tyrosine, valine, phenylalanine, isoleucine, leucine, and tryptophan) were measured by means of HPLC with fluorescence endpoint detection and pre-column sample derivatization adapted from the methods of Furst et al (1990). Norvaline was used as an internal standard. The limit of detection was $5 \mathrm{nmol} / \mathrm{ml}$ using a $10 \mu \mathrm{l}$ sample volume, and inter- and intra-assay coefficients of variation were $<15 \%$ and $<10 \%$, respectively.

\section{Data Analysis}

Mood, behavioral, and biochemical data were analyzed using SPSS 14 (SPSS Inc, Chicago, IL, USA). This study employed a within-subjects placebo-controlled crossover design. Therefore, repeated-measures analysis of variance (ANOVA) was employed where test assumptions were met (ie if data were normally distributed and variances were homogenous). For all measures, treatment (TRP + /TRP-) was entered as a within-subjects factor. For biochemical, mood, and vital signs measures, time $\left(\mathrm{T}_{0} / \mathrm{T}_{5} / \mathrm{T}_{7}\right)$ was entered as an additional within-subjects factor. For data from the AGNG, valence (happy/sad/neutral) was entered as an additional within-subjects factor. On blocks where it was clear that participants had failed to attend to the task (ie $30 \%$ hit rate or lower), or had confused the targets and distractors (ie $30 \%$ hit rate or lower and $70 \%$ false alarm rate or higher), behavioral and BOLD data for that block were excluded from analysis.

Treatment order $(\mathrm{TRP}+/ \mathrm{TRP}-$ or TRP $-/ \mathrm{TRP}+)$ was fully counterbalanced across subjects, but was initially entered as a between-subjects factor. If the main effect of treatment order and interaction of treatment order with treatment were found to be non-significant, data were collapsed across treatment order for subsequent analyses. Post hoc analyses were carried out by constructing appropriate ANOVAs for each comparison of interest. In cases where there was a departure from the assumption of homogeneity of covariance in the repeated-measures ANOVA, an epsilon $(\varepsilon)$ factor was calculated and used to adjust degrees of freedom accordingly, using the HuynhFelt procedure (Howell, 2002). As practice effects can confound crossover designs, between-subjects comparisons were conducted for first session only data if an interaction of drink order by treatment was found. Where appropriate, data were transformed prior to analysis as appropriate to reduce skew and stabilize variances, though data presented in tables and figures are untransformed values for clarity.

Analysis of BOLD fMRI data was performed using the general linear model within SPM5 (Wellcome Trust Centre for Neuroimaging, London, England; http://www.fil.ion. ucl.ac.uk/spm). Whole brain fMRI volumes were realigned to the fifth volume, co-registered with each participant's own SPGR scan, normalized to fit the Montreal Neurological Institute (MNI) standard brain template and smoothed 
using an $8 \mathrm{~mm}$ full-width half-maximum Gaussian kernel. Low-frequency artifacts were removed using a high-pass filter at $1 / 128 \mathrm{~Hz}$ and global confounds were removed using global normalization. Temporal autocorrelation intrinsic to the fMRI time-series was corrected by pre-whitening using an AR(1) process. Single-subject main effect contrast maps were created by contrasting different emotional conditions (eg happy-sad target words) and different treatment conditions (ie tryptophan depletion-sham depletion conditions). Single-subject interaction maps were created by contrasting the difference maps between emotional conditions across the two treatment conditions (eg (happy-sad target words following sham depletion)-(happy-sad target words following tryptophan depletion)). To correct for motion artifacts, the realignment parameters were modeled as regressors of no interest. We excluded from the fMRI analysis any runs on which participants exhibited movement of more than one voxel $(3 \mathrm{~mm})$ translation or $2.5^{\circ}$ rotation. We excluded from the fMRI analysis any participants for whom we were unable to include data from at least two runs on each treatment day. Visual inspection of the single-subject interaction maps confirmed an absence of obvious motion artifacts in all data analyzed at the group level.

At the second level (group analysis), regions showing significant main effects or interactions were identified through random effects analysis of the $\beta$ images from the single-subject contrast maps. We confined the Discussion to regional changes that either remained significant (at $p<0.05)$ after applying family-wise error correction for multiple comparisons, or consisted of clusters of $\geqslant 20$ voxels for which the voxel-level $t$-values corresponded to $p<0.001$ (uncorrected) located in regions included in our a priori hypotheses. However, to reduce the likelihood of type II error, we additionally report in the tables maxima reaching the $p<0.001$ (uncorrected) threshold and a minimum cluster size of 20 contained in any region. Coordinates were transformed from the MNI spatial array to the stereotaxic array of Talairach and Tournoux (1988) (http://imaging.mrc-cbu.cam.ac.uk/imaging/MniTalairach). Anatomical localization was performed with reference to the atlases of Talairach and Tournoux (1988) and Mai et al (2003), and subregions of the ventral PFC were identified as described in Ongur et al (2003).

Post hoc analyses of interactions with treatment were conducted in SPSS 14. The $\beta$ values at the peak voxel in each significant cluster (representing a significant 2-way valence $\times$ treatment interaction) were extracted for each of the relevant within-subjects simple effects (eg happy-sad target words following sham depletion, happy-sad target words following tryptophan depletion) for each participant. $T$-tests were conducted on the $\beta$ values to assess the nature of the interaction.

To analyze how regional BOLD response to positive and negative words co-varied with inter-individual variability in the effect of ATD on mood and behavior at the time of scanning, we calculated change scores on the mood rating scales (ie tryptophan depletion-sham depletion) at $\mathrm{T}_{5}$ (ie just prior to scanning), and included these as regressors when calculating the valence $\times$ treatment interaction maps for happy relative to sad targets and distractors. Similar analyses were performed for emotional bias scores (ie happy-sad stimuli) for latency and commission errors on the AGNG.

\section{RESULTS}

A total of 20 participants ( 7 male) completed both study days. The mean age was $30.5( \pm 7.3)$ years, and the mean IQ was $122.9( \pm 10.5)$. Analyses of biochemical, mood, cardiovascular, and behavioral data included all 20 participants unless otherwise stated.

\section{Plasma Amino Acids}

Due to occlusion of the venous cannulae, plasma samples could not be obtained from one participant at $T_{5}$ and $T_{7}$ on both days and three participants at $\mathrm{T}_{7}$ on both days. The following analyses are based on data from 19 participants. Administration of the TRP - mixture resulted in a decrease of $67 \%$ in the concentration of plasma tryptophan from $\mathrm{T}_{0}$ to $\mathrm{T}_{5}$, relative to an increase of $85 \%$ following TRP + (treatment $\times$ time interaction: $\mathrm{F}_{1,18}=58.7, p<0.001$ ), and a decrease of $87 \%$ in the ratio of tryptophan to the other LNAAs (TRP: $L$ LNAA) from $\mathrm{T}_{0}$ to $\mathrm{T}_{5}$, relative to a decrease of $37 \%$ following TRP + (treatment $\times$ time interaction: $\left.\mathrm{F}_{1,18}=17.1, p<0.001\right)$. Analysis of the data at $\mathrm{T}_{7}$ confirmed that tryptophan availability to the brain remained low until after the scan following TRP- (Table 1).

\section{Mood-Rating Scales}

The mean ATQ score decreased over the course of each study day, while the mean HAM-A and HAM-D scores increased from $T_{0}$ to $T_{5}$ on each study day, remaining elevated until $\mathrm{T}_{7}$. These increases were small but statistically significant (main effect of time: $\mathrm{ATQ}-\mathrm{F}_{2,38}=9.6$, $p=0.002, \quad \varepsilon=0.72 ; \quad$ HAM $-\mathrm{A}-\mathrm{F}_{2,38}=4.8, \quad p=0.023$, $\varepsilon=0.77 ;$ HAM-D $\left.-\mathrm{F}_{2,38}=6.1, p=0.05\right)$. However, no effect of time was apparent on any subscale of the POMS or the STAI, and the treatment $\times$ time interaction was nonsignificant for all mood measures (Table 1), suggesting that the subjective emotional state of the participants was not differentially affected by TRP - relative to TRP + . No participant experienced mood or anxiety changes that persisted beyond the day of testing.

\section{Cardiovascular Measures}

Blood pressure and pulse data were available for 11 participants at $T_{0}$ and $T_{5}$, but only for eight participants at $\mathrm{T}_{0}, \mathrm{~T}_{5}$, and $\mathrm{T}_{7}$. Blood pressure and pulse remained stable from $\mathrm{T}_{0}$ to $\mathrm{T}_{5}$, and were unaffected by treatment $(\mathrm{F}<1$ for both main effect of time and treatment $\times$ time interaction for all measures). A similar pattern of results was apparent at $\mathrm{T}_{7}$ (Table 1).

\section{Behavior on the Affective Go/No-Go Task}

Behavioral data are presented in Table 2. Analysis of reaction-time data revealed that participants responded significantly more quickly to emotional targets than to neutral targets (conditions $(1+3)-(5+6): \mathrm{F}_{1,19}=69.8$, $p<0.001)$. This effect was apparent for both the contrast 
Table I Plasma Amino Acid, Cardiovascular and Mood Data at Baseline, Immediately Prior to Scanning and Immediately Following Scanning

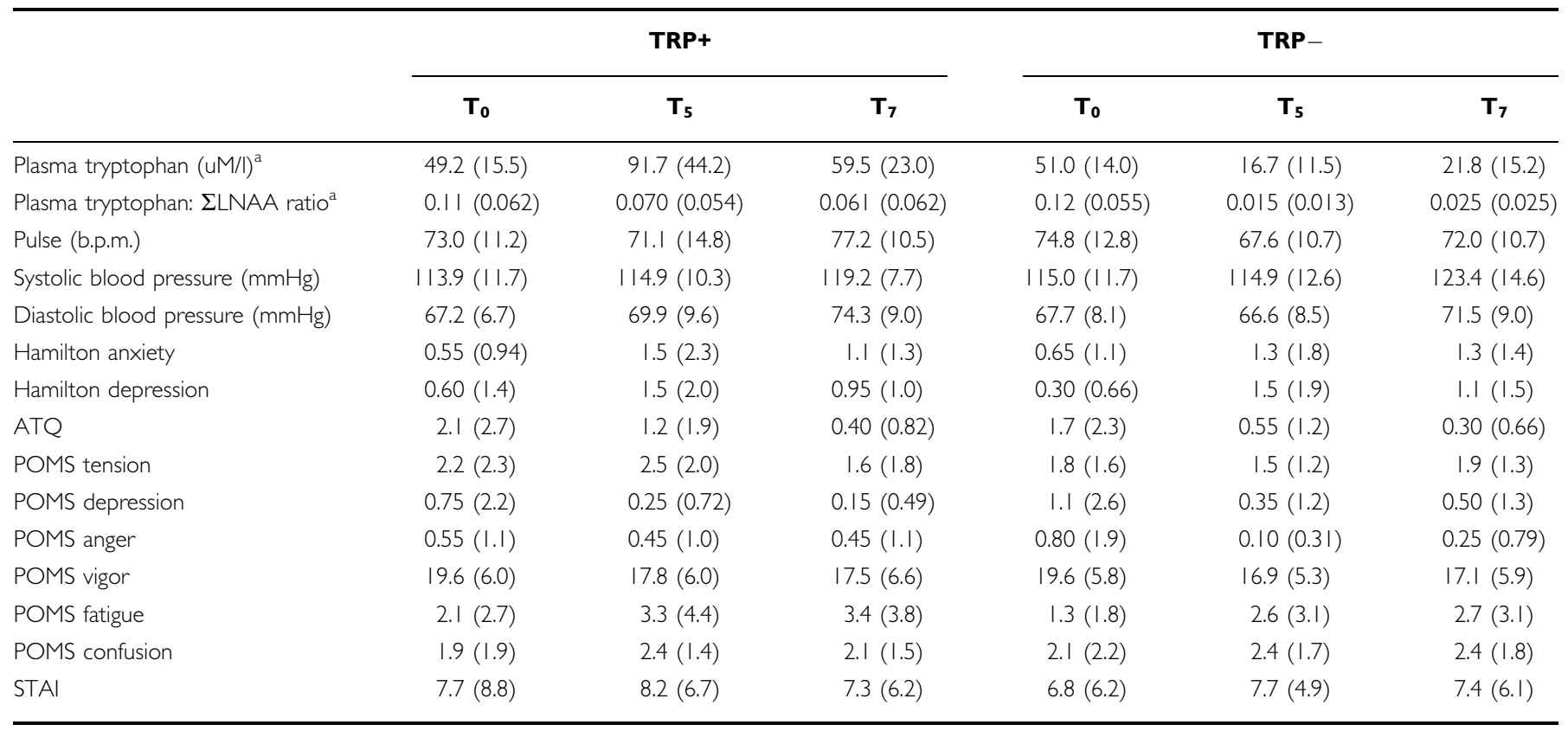

Abbreviations: ATQ, Automatic Thoughts Questionnaire; POMS, Profile of Mood States; TRP+, sham depletion condition; TRP-, tryptophan depletion condition.

Treatment $\times$ time interaction significant at $p<0.05$.

Table 2 Behavior on the Affective Go/No-Go Test

\begin{tabular}{llll}
\hline Measure & Condition & TRP+ & TRP- \\
\hline Reaction time (msec) & & \\
Happy targets, sad distractors & $601.8(59.4)$ & $613.6(58.7)$ \\
Happy targets, neutral distractors & $611.0(69.7)$ & $633.5(62.7)$ \\
Sad targets, happy distractors & $611.8(75.0)$ & $610.7(67.6)$ \\
Sad targets, neutral distractors & $615.1(63.4)$ & $632.8(66.0)$ \\
Neutral targets, happy distractors & $684.2(67.0)$ & $695.1(59.9)$ \\
Neutral targets, sad distractors & $673.7(90.3)$ & $685.1(63.2)$
\end{tabular}

Commission errors per block

\begin{tabular}{|c|c|c|}
\hline Happy targets, sad distractors & $0.47(0.65)$ & $0.41(0.53)$ \\
\hline Happy targets, neutral distractors & $0.60(0.7 I)$ & $0.63(0.88)$ \\
\hline Sad targets, happy distractors & $0.93(1.3)$ & $0.49(0.62)$ \\
\hline Sad targets, neutral distractors & $0.55(0.64)$ & $0.7 \mid(0.86)$ \\
\hline Neutral targets, happy distractors ${ }^{\mathrm{a}}$ & $1.7(1.2)$ & $1.5(0.83)$ \\
\hline Neutral targets, sad distractors ${ }^{\mathrm{a}}$ & $1.0(0.88)$ & I.4(1.5) \\
\hline
\end{tabular}

Omission errors per block

$\begin{array}{lcc}\text { Happy targets, sad distractors } & 0.83(1.2) & 0.74(0.96) \\ \text { Happy targets, neutral distractors } & 1.1(1.5) & 1.3(1.2) \\ \text { Sad targets, happy distractors } & 0.68(1.3) & 0.68(1.1) \\ \text { Sad targets, neutral distractors } & 0.87(0.97) & 0.96(1.2) \\ \text { Neutral targets, happy distractors } & 1.1(1.3) & 1.1(1.2) \\ \text { Neutral targets, sad distractors } & 1.3(1.7) & 1.2(1.3)\end{array}$

Abbreviation: TRP+, sham depletion condition; TRP-, tryptophan depletion condition.

${ }^{a}$ Following sham depletion, participants made significantly more commission errors to happy distractors than sad distractors. Following tryptophan depletion this affect was attenuated and non-significant. of happy $v s$ neutral targets (conditions 1-6: $\mathrm{F}_{1,19}=47.9$, $p<0.001$ ) and sad vs neutral targets (conditions 3-5: $\left.\mathrm{F}_{1,19}=45.3, p<0.001\right)$. However, participants responded with similar speed to happy and sad targets (conditions 2-4: $\mathrm{F}<1$ ). In none of the analyses of latency data was an interaction with treatment apparent $(p>0.2$ for all interactions).

Analysis of commission error rates revealed no main effect of emotional $v s$ neutral distractors on inappropriate responding (conditions $(1+3)-(2+4)$ : $\mathrm{F}<1$ ). Participants made significantly more inappropriate responses to happy distractors than to sad distractors (conditions 5-6: $\mathrm{F}_{1,19}=5.9, p=0.025$ ). Planned comparisons revealed that this positive emotional bias was only apparent following $\mathrm{TRP}+\left(\mathrm{t}_{19}=3.1, \quad p=0.005\right)$, and was non-significant following $\mathrm{TRP}-\left(\mathrm{t}_{19}<1\right)$. However, the interaction between treatment and valence fell short of significance $\left(F_{1,19}=2.5\right.$, $p=0.13)$.

The pattern of omission errors mirrored that of the reaction-time data. Participants missed significantly more neutral targets than emotional targets (conditions $(1+3)-(5$ $\left.+6): F_{1,19}=24.5, p<0.001\right)$, an effect that was apparent for both the contrast of happy $v s$ neutral targets (conditions $\left.1-6: \mathrm{F}_{1,19}=11.3, p<0.001\right)$ and sad $v s$ neutral targets (conditions 3-5: $\mathrm{F}_{1,19}=9.79, p<0.001$ ). However, participants responded with similar accuracy to happy and sad targets (conditions 2-4: $\mathrm{F}_{1,19}=2.2, p=0.16$ ). In none of analyses of omission error data was an interaction with treatment apparent ( $p>0.2$ for all interactions).

\section{fMRI Data}

Three participants' data were excluded due to excessive head movement. Therefore, the following analyses are based 
on data from 17 participants. Participants showed a trend toward greater translational head movement per run in the sham depletion than the tryptophan depletion condition (sham depletion: $x=0.23 \pm 0.10 \mathrm{~mm} ; y=0.52 \pm$ $0.20 \mathrm{~mm} ; \quad z=0.67 \pm 0.30 \mathrm{~mm}$; tryptophan depletion: $x=0.23 \pm 0.09 \mathrm{~mm} ; y=0.48 \pm 0.14 \mathrm{~mm} ; z=0.55 \pm 0.36 \mathrm{~mm}$; $\mathrm{F}(1,16)=3.3, p=0.088)$. There was no difference between the treatment conditions for rotational head movement per run (sham depletion: roll $=0.69 \pm 0.43^{\circ}$; pitch $=0.34 \pm 0.16^{\circ}$; yaw $=0.28 \pm 0.12^{\circ}$; tryptophan depletion: roll $=0.63 \pm 0.42^{\circ}$; pitch $=0.37 \pm 0.13^{\circ}$; yaw $=0.27 \pm 0.11^{\circ} ; \mathrm{F}<1$ ).

Tables 3 and 4 list regions showing task-related differences averaging across treatment condition (ie main effects), while Tables 5 and 6 list regions where the task- related regional response was modulated by treatment (ie interactions).

Emotional relative to neutral targets. Regions showing increased BOLD response to emotional relative to neutral targets (conditions $(1+3)-(5+6)$ ), included posterior cingulate and ventromedial PFC (BA 10P-Ongur et al, 2003), both of which reached significance at $p<0.05$ (corrected). Additionally, areas of the pregenual ACC (BA 32ac-Ongur et al, 2003), mid-cingulate cortex and superior temporal gyrus (STG) also showed increased BOLD response to emotional relative to neutral targets. Performing the reverse contrast revealed increased BOLD response to neutral relative to emotional targets in the left

Table 3 Regions Showing a Main Effect (ie Independent of Depletion Condition) of Emotional Content on Regional BOLD Response to Target Stimuli

\begin{tabular}{|c|c|c|c|c|c|c|}
\hline \multirow[b]{2}{*}{ Region } & \multirow[b]{2}{*}{ Laterality } & \multicolumn{3}{|c|}{ Stereotaxic coordinates } & \multirow[b]{2}{*}{ Cluster size } & \multirow[b]{2}{*}{ Z-value } \\
\hline & & $\mathbf{x}$ & $\mathbf{Y}$ & $\mathbf{Z}$ & & \\
\hline Posterior cingulate C & M & 0 & -51 & 25 & $1483^{\dagger}$ & $5.00 *$ a \\
\hline Ventromedial frontal polar C & M & -4 & 58 & -1 & $270^{\dagger}$ & $4.98^{*}$ a \\
\hline Superior temporal G & $R$ & 48 & -63 & 27 & 47 & $3.62^{\mathrm{a}}$ \\
\hline \multicolumn{7}{|l|}{ Neutral > emotional targets } \\
\hline Dorsal anterior cingulate C & $R$ & 6 & 12 & 44 & $521^{\dagger}$ & $5.4 l^{*} \cdot \mathrm{b}$ \\
\hline Dorsolateral PFC & $L$ & -42 & 3 & 26 & $1318^{\dagger}$ & $4.99 *$, b \\
\hline Fusiform G & $\mathrm{R}$ & 38 & -51 & -19 & 56 & $4.30^{b}$ \\
\hline Medial cerebellum & $L$ & -8 & -79 & -28 & 116 & $4.06^{b}$ \\
\hline Superior parietal $C$ & $\mathrm{R}$ & 40 & -41 & 41 & 106 & $4.06^{b}$ \\
\hline Occipital C & $\mathrm{R}$ & 44 & -69 & -12 & 79 & $3.86^{\mathrm{b}}$ \\
\hline Superior parietal C & $L$ & -22 & -66 & 44 & $206^{\dagger}$ & $3.84^{b}$ \\
\hline Dorsolateral prefrontal C & $R$ & 38 & 3 & 53 & 21 & $3.78^{\mathrm{b}}$ \\
\hline Parietal C & $\mathrm{R}$ & 28 & -58 & 47 & 99 & $3.67^{b}$ \\
\hline Occipital C & $\mathrm{R}$ & 28 & -70 & 29 & 41 & $3.60^{b}$ \\
\hline \multicolumn{7}{|l|}{ Happy $>$ sad targets } \\
\hline
\end{tabular}

Abbreviations: BA IOP, Brodmann Area 10 polar (see Ongur et al, 2003); BOLD, blood oxygenation-level dependent; C, cortex; FWE, family-wise error; G, gyrus; $L$, left; $M$, midline; R, right.

Coordinates correspond to the stereotaxic array of Talairach and Tournoux (1988) and denote the distance in mm from the anterior commissure, with positive

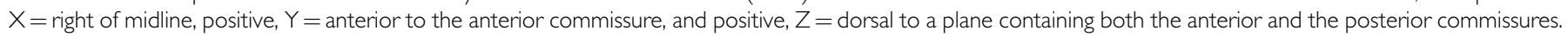
Italic font denotes that the maximum was contained within an a priori specified region of interest.

*Peak voxel significant at $p<0.05$ (FWE corrected for multiple comparisons); ${ }^{\dagger}$ cluster significant at $p<0.05$ (corrected in terms of spatial extent).

${ }^{\text {a }}$ arameter estimates negative relative to rest.

${ }^{b}$ Parameter estimates positive relative to rest. 
Table 4 Regions Showing a Main Effect (ie Independent of Depletion Condition) of Emotional Content on Regional BOLD Response to Distractor Stimuli

\begin{tabular}{|c|c|c|c|c|c|c|}
\hline \multirow[b]{2}{*}{ Region } & \multirow[b]{2}{*}{ Laterality } & \multicolumn{3}{|c|}{ Stereotaxic coordinates } & \multirow[b]{2}{*}{ Cluster size } & \multirow[b]{2}{*}{ Z-value } \\
\hline & & $\mathbf{x}$ & $\mathbf{Y}$ & $\mathbf{Z}$ & & \\
\hline Cerebellum & L & -24 & -46 & -30 & 23 & $3.9^{\mathrm{a}}$ \\
\hline Occipital C & L & -10 & -53 & -7 & 32 & $3.68^{b}$ \\
\hline \multicolumn{7}{|l|}{ Neutral > emotional distractors } \\
\hline Ventrolateral prefrontal C & L & -44 & 33 & 8 & $976^{\dagger}$ & $5.38^{*}$ a \\
\hline Ventrolateral prefrontal C & $\mathrm{R}$ & 46 & 31 & 8 & $724^{\dagger}$ & $5.05^{*} \cdot \mathrm{a}$ \\
\hline Superior parietal C & $\mathrm{R}$ & 28 & -50 & 41 & 105 & $4.74^{\mathrm{a}}$ \\
\hline Anterior cingulate sulcal C & M & 4 & 29 & 35 & $612^{\dagger}$ & $4.67^{\mathrm{a}}$ \\
\hline Parieto-occipital transition zone & L & -30 & -81 & 19 & 72 & $3.82^{b}$ \\
\hline Medial cerebellum & L & -12 & -77 & -25 & 31 & $3.78^{\mathrm{a}}$ \\
\hline Occipital C & L & -38 & -79 & 4 & 32 & $3.69^{\mathrm{a}}$ \\
\hline Medial cerebellum & $\mathrm{R}$ & 16 & -79 & -26 & 102 & $3.67^{\mathrm{a}}$ \\
\hline Precentral G & $L$ & -40 & 3 & 26 & 25 & $3.61^{\mathrm{a}}$ \\
\hline
\end{tabular}

Abbreviations and interpretation of stereotaxic coordinates as in Table 3.

Italic font denotes that the maximum was contained within an a priori specified region of interest.

*Peak voxel significant at $p<0.05$ (FWE corrected for multiple comparisons); ${ }^{\dagger}$ Cluster significant at $p<0.05$ (corrected in terms of spatial extent).

aParameter estimates positive relative to rest.

barameter estimates negative relative to rest.

dorsolateral PFC (DLPFC) and right dorsal anterior cingulate cortex (dACC), both of which achieved significance at $p<0.05$ (corrected), as well as right DLPFC, right parietal cortex, right lateral orbitofrontal cortex (OFC), and left inferior temporal gyrus (Table 3).

BOLD response to emotional relative to neutral targets was modulated by ATD in the left ventral putamen, left thalamus, left amygdala, right parahippocampal gyrus, bilateral parietal operculum, and right anterior insula/ putamen (Table 5). Post hoc analysis of the parameter estimates for these interactions revealed a greater BOLD response to emotional relative to neutral targets following TRP-, with either the opposite pattern of response or no difference between emotional and neutral targets following TRP + (Figures 1a and b).

BOLD response to emotional relative to neutral targets was also modulated by ATD in the right DLPFC, though the interaction was in the opposite direction (Table 5). Post hoc analysis of the parameter estimates for this interaction revealed a greater BOLD response to neutral relative to emotional targets following TRP-, with a difference in the same direction, but of lesser magnitude, following TRP + (Figures $1 \mathrm{c}$ and $\mathrm{d}$ ).

Happy relative to sad targets. Increased BOLD response to happy relative to sad targets was apparent in the right DLPFC and left ventrolateral PFC (VLPFC) (Table 3). BOLD response to happy relative to sad targets was modulated by
ATD in the right STG (Table 5). Post hoc analysis of the parameter estimates revealed a greater BOLD response to happy relative to sad targets following TRP +, with the opposite pattern of response following TRP-.

Emotional relative to neutral distractors. Within the a priori specified regions of interest, only the ventromedial PFC (BA 10P - Ongur et al, 2003) showed increased BOLD response to emotional relative to neutral distractors (conditions $(1+3)-(2+4)$ ). However, performing the reverse contrast revealed a number of areas that showed increased BOLD response to neutral relative to emotional distractors, including bilateral VLPFC, which achieved significance at $p<0.05$ (corrected), as well as bilateral parietal cortex and right dACC (Table 4).

BOLD response to emotional relative to neutral distractors was modulated by ATD in the right STG, left posterior hippocampus, bilateral caudate, right inferior temporal gyrus, right VLPFC, and left posterior cingulate (retrosplenial) cortex (Table 6). Post hoc analysis of the parameter estimates for these interactions revealed a greater BOLD response to emotional relative to neutral distractors following TRP-, with either the opposite pattern of response or no difference between emotional and neutral distractors following TRP + (Figures 2a and $\mathrm{b}$ ).

BOLD response to emotional relative to neutral distractors was also modulated by ATD in the right AACC, though the interaction was in the opposite direction. The peak voxel 
Table 5 Regions Where the Effect of Emotional Content on BOLD Response to Target Stimuli was Modulated by Tryptophan Depletion (ie Treatment $\times$ Condition Interactions)

\begin{tabular}{|c|c|c|c|c|c|c|}
\hline \multirow[b]{2}{*}{ Region } & \multirow[b]{2}{*}{ Laterality } & \multicolumn{3}{|c|}{ Stereotaxic coordinates } & \multirow[b]{2}{*}{ Cluster size } & \multirow[b]{2}{*}{ Z-value } \\
\hline & & $\mathbf{x}$ & $\mathbf{Y}$ & $\mathbf{Z}$ & & \\
\hline \multicolumn{7}{|l|}{ Emotional-neutral targets TRP $->\operatorname{TRP}+$} \\
\hline Parietal operculum & L & -48 & -34 & 24 & 88 & $4.88^{\mathrm{a}}$ \\
\hline Ventral putamen & L & -32 & -13 & 3 & $223^{\dagger}$ & $4.09^{\mathrm{a}}$ \\
\hline Medial cerebellum & $\mathrm{L}$ & -16 & -46 & -28 & 27 & $3.6^{\mathrm{a}}$ \\
\hline Thalamus & $R$ & 16 & -23 & -2 & 36 & $3.55^{\mathrm{a}}$ \\
\hline Parietal operculum & $\mathrm{R}$ & 36 & -28 & 14 & 26 & $3.49^{\mathrm{b}}$ \\
\hline Putamen & $L$ & -24 & 10 & 5 & 69 & $3.46^{\mathrm{a}}$ \\
\hline Hippocampal formation & L & -24 & -29 & -7 & 22 & $3.46^{\mathrm{a}}$ \\
\hline \multicolumn{7}{|l|}{ Emotional-neutral targets TRP+>TRP- } \\
\hline Dorsolateral prefrontal C & $R$ & 40 & 35 & 31 & 23 & $3.86^{c}$ \\
\hline \multicolumn{7}{|l|}{ Happy-sad targets TRP $+>$ TRP -} \\
\hline Superior temporal G & $R$ & 57 & -27 & 3 & 95 & $4.22^{\mathrm{d}}$ \\
\hline
\end{tabular}

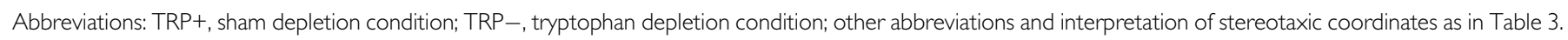
Italic font denotes that the maximum was contained within an a priori specified region of interest.

'Cluster significant at $p<0.05$ (corrected in terms of spatial extent).

anteraction characterized by increased BOLD response to emotional targets following tryptophan depletion (see Figure Ib).

binteraction characterized by an attenuation of deactivation to emotional targets following tryptophan depletion.

"Interaction characterized by increased BOLD response to neutral targets following tryptophan depletion (see Figure Id).

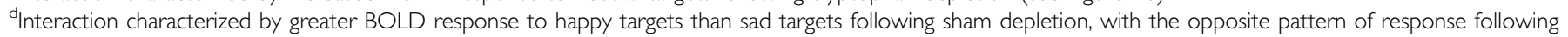
tryptophan depletion.

of this interaction was contained within an area that showed a greater response to neutral relative to emotional distractors (see above and Tables 4 and 6). Post hoc analysis of the parameter estimates for the interaction qualified the main effect, revealing that the greater BOLD response to neutral relative to emotional distractors was only present following $\mathrm{TRP}-$, with no differential response to emotional relative to neutral distractors following TRP + (Figures $2 \mathrm{c}$ and $\mathrm{d}$ ).

Happy relative to sad distractors. No areas within the a priori defined ROIs showed a greater BOLD response to happy relative to sad distractors, or for the reverse contrast, at $p<0.001$ (uncorrected). The BOLD response to happy relative to sad distractors was modulated by ATD in the posterior cingulate cortex (Table 6). Post hoc analysis of the parameter estimates revealed a greater BOLD response to happy distractors compared to sad distractors following $\mathrm{TRP}+$, with the opposite pattern of response following TRP-.

\section{Correlation of Mood and Behavioral Data with Bold Signal Change Following ATD}

Change in $\mathrm{T}_{5}$ STAI score correlated significantly with change in BOLD response to happy relative to sad distractors following ATD in the right caudate $[x=10$, $y=18, z=8$ ], $z=4.48$, cluster size 156; Figures $3 \mathrm{a}$ and $\mathrm{b}$ ); participants who became more anxious following TRPshowed a greater response to negative relative to positive distractors following TRP-. A more spatially restricted relationship was also present in the left caudate. There were no regions in which change in anxiety score correlated significantly with change in BOLD response to happy relative to sad targets. There were also no areas in which change in BOLD response to happy relative sad stimuli following ATD correlated significantly with change in emotional bias in terms of either latency or commission errors.

\section{DISCUSSION}

This is the first study to examine the effect of 5-HT depletion on neural and behavioral responses to emotional words. A highly significant attentional bias toward positive distractors evident under sham depletion was attenuated following tryptophan depletion, and this change was associated with increased neurophysiological responses to emotionally valenced $v s$ neutral words in the ventral striatum, hippocampal/parahippocampal cortex, anterior insula and VLPFC, and to negative $v s$ positive words in the STG and posterior cingulate cortex. All of these regions have been implicated in the pathophysiology of major depression, a condition associated with both deficits in 
Table 6 Regions Where the Effect of Emotional Content on BOLD Response to Distractor Stimuli was Modulated by Tryptophan Depletion (ie Treatment $\times$ Condition Interactions)

\begin{tabular}{|c|c|c|c|c|c|c|}
\hline \multirow[b]{2}{*}{ Region } & \multirow[b]{2}{*}{ Laterality } & \multicolumn{3}{|c|}{ Stereotaxic coordinates } & \multirow[b]{2}{*}{ Cluster size } & \multirow[b]{2}{*}{ Z-value } \\
\hline & & $\mathbf{x}$ & $\mathbf{Y}$ & $\mathbf{Z}$ & & \\
\hline Superior temporal G & $R$ & 38 & -55 & 18 & 127 & $4.26^{\mathrm{a}}$ \\
\hline Posterior cingulate $C$ & $L$ & -24 & -53 & 19 & $356^{\dagger}$ & $4.21^{\mathrm{a}}$ \\
\hline Dorsal caudate & $L$ & -16 & -3 & 24 & 135 & $3.98^{\mathrm{a}}$ \\
\hline Inferior temporal G & $R$ & 36 & -9 & -21 & 51 & $3.59^{\mathrm{a}}$ \\
\hline Frontal operculum & $\mathrm{R}$ & 34 & । & 17 & 77 & $3.57^{\mathrm{a}}$ \\
\hline Precentral gyrus & $\mathrm{R}$ & 32 & -23 & 44 & 50 & $3.5^{\mathrm{b}}$ \\
\hline Ventrolateral prefrontal C & $R$ & 34 & 28 & 12 & 36 & $3.5^{\mathrm{a}}$ \\
\hline \multicolumn{7}{|c|}{ Emotional-neutral distractors TRP $+>T R P-$} \\
\hline Anterior cingulate sulcal C & M & 2 & 25 & 36 & $170^{\dagger}$ & $3.73^{c}$ \\
\hline \multicolumn{7}{|c|}{ Happy-sad distractors TRP $+>$ TRP- } \\
\hline Posterior cingulate $C$ & M & 4 & -32 & 16 & 27 & $3.39^{d}$ \\
\hline
\end{tabular}

Abbreviations: TRP+, sham depletion condition; TRP-, tryptophan depletion condition; other abbreviations and interpretation of stereotaxic coordinates as in Table 3. Italic font denotes that the maximum was contained within an a priori specified region of interest.

${ }^{\dagger}$ Cluster significant at $p<0.05$ (corrected in terms of spatial extent).

anteraction characterized by increased BOLD response to emotional distractors following tryptophan depletion (see Figure 2b).

bInteraction characterized by an attenuation of deactivation to emotional distractors following tryptophan depletion.

'Interaction characterized by increased BOLD response to neutral distractors following tryptophan depletion (see Figure 2d).

${ }^{d}$ Interaction characterized by greater BOLD response to happy targets than sad distractors following sham depletion, with the opposite pattern of response following tryptophan depletion.

serotonergic function and loss of the normal attentional bias toward positive stimuli on the AGNG.

Most of the areas in which tryptophan depletion increased neural responses to emotional relative to neutral stimuli receive moderate-to-high densities of serotonergic projections from the dorsal and/or median raphe nuclei (Jacobs and Azmitia, 1992; Varnas et al, 2004). Multiple 5HT receptor subtypes are present in each region, some of which when stimulated exert hyperpolarizing (ie inhibitory) effects on the neurons where they are expressed, and some of which exert depolarizing (ie excitatory) effects (Andrade, 1998; Peroutka et al, 1990). Methods were not available that would allow non-invasive assessment of central 5-HT transmission or determination of the specific neurochemical mechanisms underlying the increased neurophysiological responsiveness to emotional stimuli observed during tryptophan depletion in these regions. However, it has been argued (Meeter et al, 2006) that the net effect of tonic 5-HT transmission is to hyperpolarize glutamatergic neurons (at least in the hippocampus), primarily via the $5-\mathrm{HT}_{1 \mathrm{~A}}$ receptor, but also via $5-\mathrm{HT}_{3}$ and $5-\mathrm{HT}_{6}$ receptors. It is therefore conceivable that the cause of increased responsiveness of these subcortical structures to emotional stimuli following 5-HT depletion was a loss of inhibitory tone provided by these $5-\mathrm{HT}$ receptor subtypes.
Alternatively, it is possible that tryptophan depletion increased neural responses to emotional words via a decrease in activity in areas that regulate limbic activity. Both the DLPFC and AACC showed relatively attenuated activity to emotional words following tryptophan depletion (Figures $1 \mathrm{~d}$ and $2 \mathrm{~d}$ and Tables 5 and 6). Both of these regions are thought to be important in regulating activity in limbic structures such as the amygdala and hippocampus (reviewed in Drevets and Price, 2005). For example, individuals with major depression show increased amygdala activity and decreased DLPFC activity, as well as reduced effective connectivity between these two structures, in particular during emotional processing (Siegle et al, 2002). However, since direct projections from the dorsal PFC to the amygdala are relatively sparse, this regulation is presumably mediated by other regions, possibly more ventral aspects of the PFC, which receives abundant projections from the dorsolateral and dorsomedial PFC (Ongur et al, 2003; Ongur and Price, 2000). The pattern of findings that we observed, specifically increased limbic responses and decreased dorsal PFC responses to emotional stimuli following tryptophan depletion, suggests that 5-HT may modulate the 'top-down' regulation of limbic circuits.

The specific anatomical regions where physiological responses to emotional stimuli increased during tryptophan 

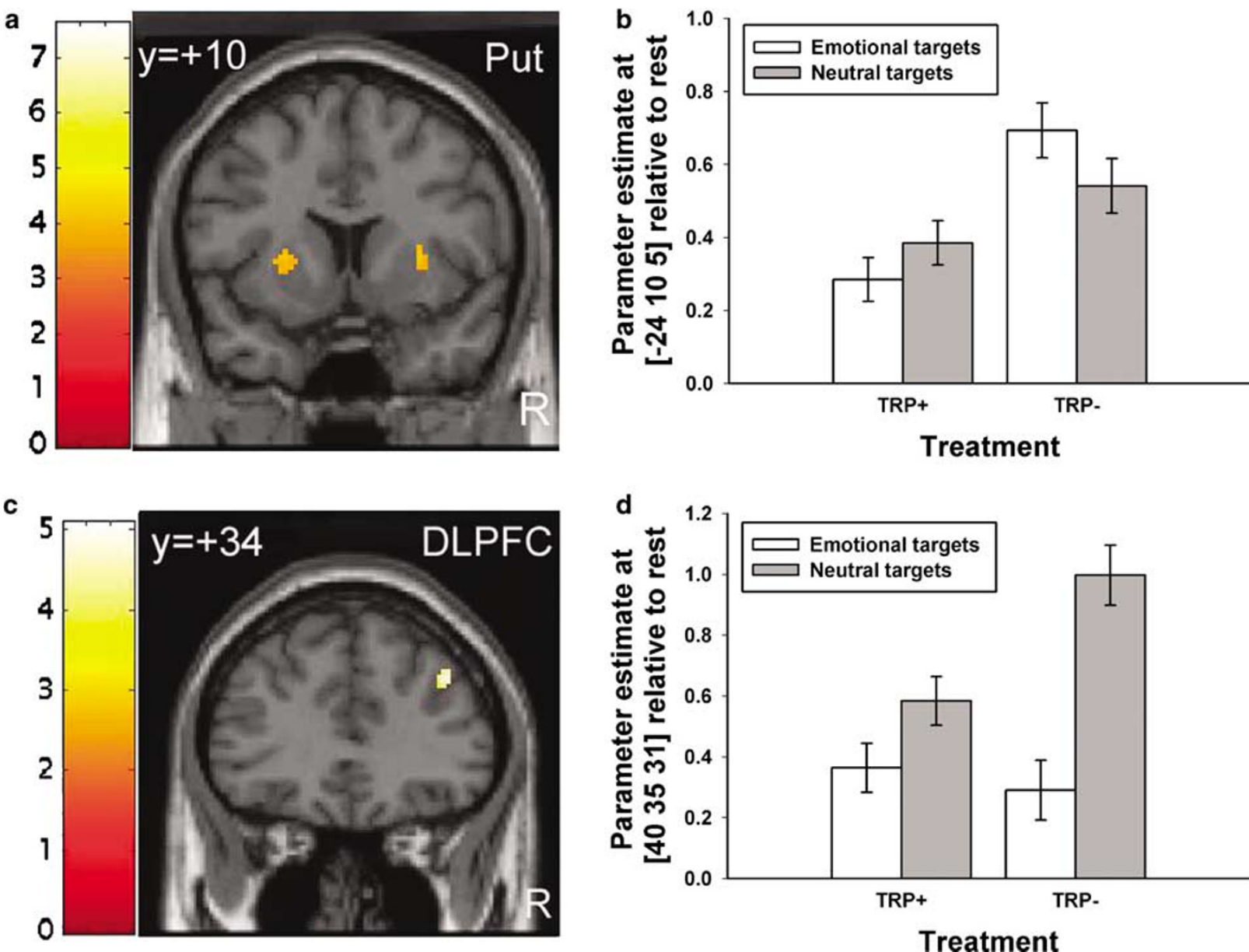

Figure I Effect of tryptophan depletion on neural responses to emotional relative to neutral target words. (a) Greater response to emotional relative to neutral target words following tryptophan depletion in the left putamen $([x=-24, y=10, z=5]$, peak $Z$-score $=3.46)$ and right insula/putamen $([x=30$, $y=8, z=5]$, peak $Z$-score =3.66). (c) Greater response to neutral relative to emotional target words following tryptophan depletion in the right dorsolateral prefrontal cortex $([x=40, y=35, z=31]$, peak $Z$-score $=3.86)$. Effects in (a) and (c) were significant at $p<0.00$ I, minimum cluster size 20 voxels. Color bars indicate $t$-values and images are thresholded at $p<0.00 \mathrm{I}$. (b and d) Plots of parameter estimates relative to rest for emotional and neutral target words under tryptophan and sham depletion conditions for peak voxels in the left putamen (b) and right dorsolateral prefrontal cortex (d). Error bars represent I SED between emotional and neutral targets.

depletion have been implicated in experimentally induced sadness (Drevets and Raichle, 1992; Harmer et al, 2003; Mayberg et al, 1999) and major depression (Drevets et al, 1992). PET studies have demonstrated that glucose metabolism is increased and/or that gray matter volume is decreased in these structures in unipolar-depressed individuals (Drevets and Price, 2005). The metabolic activity in these areas appears to normalize during symptom remission. For example, physiological activity in the amygdala and anterior insula decreased following effective treatment with SSRIs in depressed patients (Drevets et al, 2002; Drevets and Raichle, 1992; Mayberg et al, 1999), and also appeared decreased in the anterior insula and VLPFC in spontaneously remitted MDD individuals and healthy controls compared with depressed MDD individuals (Drevets et al, 1992). The anterior insula shares extensive anatomical connectivity with the amygdala, hippocampal/ parahippocampal cortices, ventromedial striatum, and thalamus. The limbic-cortical-striatal-pallidal-thalamic circuit formed by these regions also interacts with other orbitomedial PFC, temporal lobe (eg, STG, parahippocampal cortex), and cingulate regions (mid- and posterior cingulate cortices) to form the visceromotor network, which modulates the endocrine, autonomic, and experiential aspects of emotional behavior (Kondo et al, 2005; Ongur et al, 2003; Ongur and Price, 2000).

The two regions in which tryptophan depletion increased BOLD response to negative relative to positive words, the STG, and posterior cingulate cortex, have also consistently been implicated in unipolar depression (Drevets et al, 2002; Nugent et al, 2006). Both areas share extensive, monosynaptic anatomical connections with the orbitomedial PFC regions associated with the visceromotor network (Ongur et al, 2003), and have been implicated in verbal processing, particularly the processing of emotionally valenced verbal stimuli (Cato et al, 2004; Kuchinke et al, 2005; Maddock et al, 2003).

The most striking behavioral effect in this study was the highly significant positive bias on the AGNG. Participants made significantly more inappropriate responses to positive stimuli than negative stimuli. Within the context of AGNG tasks, such an increase in this type of error is interpreted as indicating that the distractor stimulus is capturing attention, reducing the capability for selectively attending to the 
a

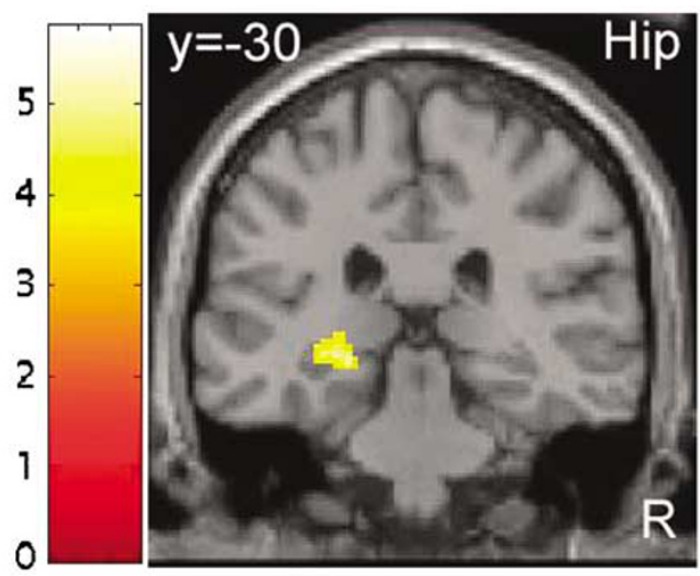

b
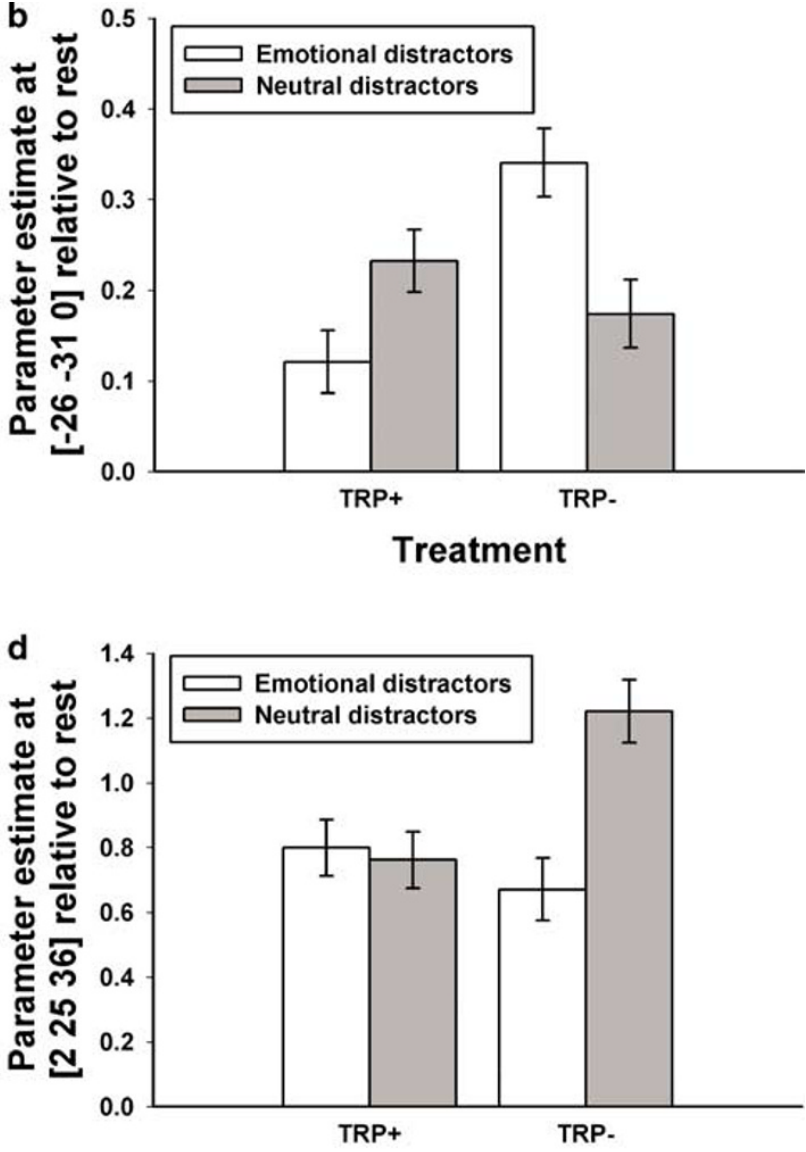

Treatment

Figure 2 Effect of tryptophan depletion on neural responses to emotional relative to neutral distractor words. (a) Greater response to emotional relative

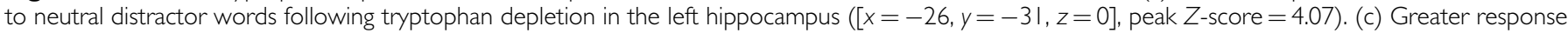
to neutral relative to emotional target words following tryptophan depletion in dorsal anterior cingulate cortex $([x=2, y=25, z=36]$, peak $Z$-score $=3.73)$. Effects in (a) and (c) were significant at $p<0.00 \mathrm{I}$, minimum cluster size 20 voxels. Color bars indicate $t$-values and images are thresholded at $p<0.00 \mathrm{I}$. ( $b$ and d) Plots of parameter estimates relative to rest for emotional and neutral distractor words under tryptophan and sham depletion conditions for peak voxels in the left hippocampus (b) and dorsal anterior cingulate (d). Error bars represent I SED between emotional and neutral distractors.

relevant stimulus-set. Biases toward positive stimuli in healthy volunteers have been reported previously, in particular by Erickson et al (2005), who used a very similar AGNG task. They suggested that this bias on the AGNG might represent a normal suppression of attention to negative stimuli. In contrast, the opposite bias (toward negative stimuli) was observed in unipolar depressives in the same study. Thus, the normal attentional bias toward positive relative to negative stimuli was hypothesized to confer resilience against depression. In the present study, this positive bias was attenuated and non-significant following tryptophan depletion, though the interaction of attentional bias with depletion condition fell short of statistical significance. These data therefore tentatively suggest that serotonergic function may play a role in mediating resilience to negative stimuli in never-depressed healthy individuals.

When we included change in subjective anxiety state as a covariate in the analysis of neural responses to positive relative to negative distractors, a striking relationship was observed in the right caudate (and possibly also the left caudate, although the spatial extent on the left was below our significance threshold of 20-voxels). Participants who became more anxious following tryptophan depletion also showed an increase in neurophysiological response in the caudate to negative relative to positive distractors. Notably, BOLD signal response to emotional words was increased following tryptophan depletion in the same region. Data from human and animal studies implicate the caudate in modulating anxiety responses to stress or threat (reviewed in Charney and Drevets, 2002). For example, studies in experimental animals suggested that dopamine release and turnover increased in the mesoaccumbens projections during mild-to-moderate stress, and in the nigrostriatal projections during more severe stress (Deutch and Roth, 1990; Inoue et al, 1994). In humans, one study suggested that during amphetamine challenge the magnitude of DA release in the ventral striatum correlated inversely with anxiety ratings in healthy humans (Drevets et al, 2001). Moreover, the magnitude of dopamine release in the striatum has been shown to be modulated by $5-\mathrm{HT}_{2 \mathrm{~A}}$ receptor stimulation (Pehek et al, 2006; Porras et al, 2002; Yan, 2000), suggesting a mechanism through which the altered serotonergic function associated with tryptophan depletion may exert secondary effects on other neurotransmitter systems and thereby influence anxiety symptoms. 
a

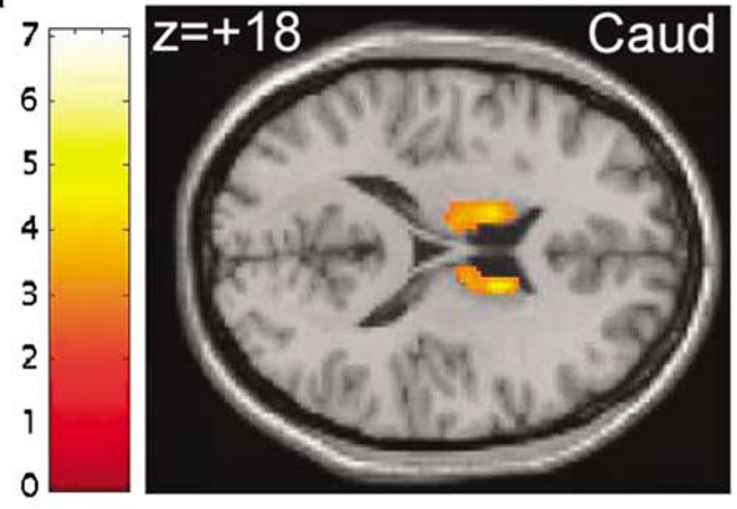

b

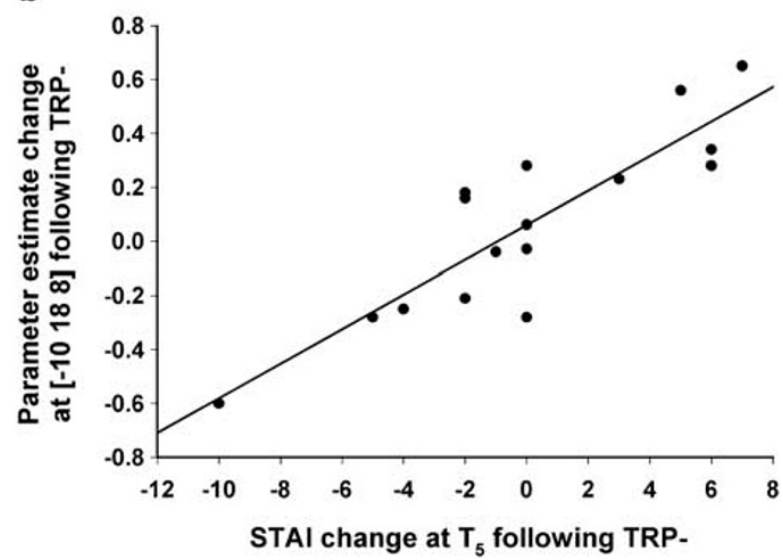

Figure 3 Relationship between tryptophan depletion-elicited anxiety and tryptophan depletion-elicited bias toward negative distracting stimuli in the caudate. (a) Across participants, tryptophan depletion-elicited anxiety covaried strongly with tryptophan depletion-elicited response to negative relative to positive distractors in the left caudate $((x=-10, y=18, z=8)$, peak $Z$-score $=4.48)$, with a similar, but more spatially restricted relationship, on the right. Participants who became more anxious following tryptophan depletion showed a greater caudate response to negative relative to positive distracting stimuli. The effect in the left caudate was significant at $p<0.00 \mathrm{I}$, minimum cluster size 20 voxels. Color bars indicate $t$-values and the image is thresholded at $p<0.005$ for display purposes. (b) Correlation between tryptophan depletion-elicited change in parameter estimate at the peak voxel in the left caudate for the sad-happy distractors contrast and tryptophan depletion-elicited change in subjective anxiety rating $(r=0.874, p<0.0000 \mathrm{I})$.

Finally, the caudate responds preferentially to salient stimuli, whether or not such stimuli are associated with reward (Knutson et al, 2003; Schultz et al, 2003; Zink et al, 2006, 2004). Therefore, it is possible that this relationship may reflect the increased saliency of negatively valenced distractors in those participants who became more anxious following tryptophan depletion.

Our findings replicated the results of Elliott et al (2000), who reported that responding to emotional relative to neutral words resulted in increased BOLD response in the pregenual ACC in healthy humans. In the present study, for the same contrast using the same task, we found increased BOLD response in a pregenual ACC region situated close to that identified by Elliott et al (2000) (Table 3). However, the parameter estimates in this region were negative relative to rest for both emotional and neutral targets, suggesting that the effect Elliott et al reported may be mediated by an attenuation of deactivation to emotional words. Elliott et al (2002) also reported that patients with unipolar depression showed an attenuated hemodynamic response in the pregenual ACC to emotional targets. Our results suggest the hypothesis that depressed individuals show equivalent deactivation to emotional and neutral targets in the pregenual ACC, which may reflect a difficulty in regulating subcortical activity in response to emotional stimuli. However, in the present study this effect in the pregenual ACC was of similar magnitude in the sham depletion and tryptophan conditions, suggesting that this finding in depression did not simply reflect a deficit in 5-HT transmission, and may instead have resulted from the depressed mood or the pathophysiology associated with MDD, since few of our participants reported mood change following tryptophan depletion.

The lack of effect of tryptophan depletion on subjective mood state in these never-depressed, healthy humans with no first-degree relatives with mood or anxiety disorders is consistent with previous research (Bell et al, 2005). Few studies that have not specifically selected volunteers with a personal or family history of mood disorders have reported emotional changes following tryptophan depletion. However, despite the lack of subjective effects on mood, tryptophan depletion attenuated a bias toward positive distractors and resulted in a bias in the neurophysiological response toward emotional stimuli in limbic-corticalstriatal-pallidal-thalamic circuits previously implicated in normal and pathological emotional processing (Phillips et al, 2003a, b). These effects of tryptophan depletion on behavioral and neural responses to other types of emotional stimuli in the absence of subjective mood effects are consistent with several other reports in the literature, which found tryptophan depletion-induced changes in the hemodynamic responses to emotionally expressive face stimuli or to spurious negative feedback provided during probabilistic reversal learning (Cools et al, 2005a; Harmer et al, 2003; Murphy et al, 2002; van der Veen et al, 2007).

Several limitations of our study merit comment. First, although we used a relatively homogenous sample of healthy volunteers with no personal history of psychiatric disease and no first-degree relatives with mood or anxiety disorders, we included fewer than 20 participants in the neuroimaging analyses. Therefore, these data should be treated with caution until independently replicated. Second, it is possible that vascular effects may have confounded the neuroimaging results; 5-HT receptors are known to be involved in vasoconstriction and vasodilation (Saxena and Villalon, 1990), although different receptors exert distinct effects on vascular tone. However, the interactions between depletion condition and emotional valence that we observed were not simply confined to areas that showed a main effect, which might be expected if 5-HT depletion had simply increased or decreased the amplitude of the hemodynamic response function independent of neural activity.

Third, participants showed a trend toward greater translational head movement per run in the sham depletion than the tryptophan depletion condition. However, the average difference in translational movement per run 
between the treatment conditions was approximately $0.15 \mathrm{~mm}$, representing approximately one-twentieth of a voxel. Furthermore, our statistical model included the movement parameters for each run at the subject level, which should have removed most of the variance in the contrast images that was associated with head movement. Therefore, we do not believe that the interpretation of our fMRI data is likely to be confounded by differences in head movement between the treatment conditions.

Finally, participants in the present study made more omission errors when responding to neutral words than when responding to emotional words, suggesting that the neutral and emotional conditions were imprecisely matched for difficulty. This effect was unexpected, since the neutral and emotional words were carefully matched for imageability, length, and frequency, and were identical to those used by Elliott et al (2000), who did not report such an effect. However, this result may explain the increased hemodynamic response we observed to neutral relative to emotional stimuli in the DLPFC and dACC, effects also not reported by Elliott et al (2000), since these regions have been implicated in error-likelihood signaling (Brown and Braver, 2005). To avoid this confound, future studies might benefit from employing event-related designs so that trials on which participants responded incorrectly could be excluded from analysis.

In summary, 5-HT depletion increased BOLD response to emotional stimuli generally in many structures implicated in unipolar depression, and increased responses specifically to negative stimuli in areas implicated in the processing of emotionally valenced verbal information. Furthermore, inter-individual variability in the increase in subjective anxiety following tryptophan depletion was strongly correlated with the increase in hemodynamic activity in the caudate in response to negative distracting stimuli. These data suggest that 5 -HT depletion subtly influences the neural processing of emotionally valenced stimuli, in particular increasing responses to emotional stimuli in subcortical structures such as the amygdala, caudate, and parahippocampal gyrus, and biasing activity toward negative stimuli in the posterior cingulate and temporal cortex. Notably, these changes occurred even in the absence of overt effects on participants' mood state, although tryptophan depletion did attenuate a bias toward positive distracting stimuli. These data suggest a neural mechanism by which hypofunction of the 5-HT system, such as is hypothesized to exist in MDD, may result in a maladaptive bias toward negative stimuli, by increasing responsivity to emotional stimuli in subcortical limbic structures and biasing emotional information processing in the temporal cortex and posterior cingulate cortex toward negative stimuli, and may also provide insight into the neural modulation of resilience in never-depressed healthy volunteers.

\section{ACKNOWLEDGEMENTS}

This research was supported by the Intramural Research Program of the NIMH. JPR was supported by the NIHCambridge Health Science Scholars Program. We thank Judy Starling for preparation of the amino acid mixtures,
Mike Franklin for analysis of the plasma amino acids, Harvey Iwamoto for programming the AGNG, Rebecca Elliott, and Judy Rubinsztein for kindly providing the original word lists for the AGNG, Jeanette Black and Renee Hill for radiographer support, the nurses of ward 5 SouthWest for their dedicated clinical support, Karl Friston for guidance regarding fMRI analysis and Predrag Petrovic for helpful discussion of the manuscript. We thank Joan Williams and Paul Carlson for help with recruitment and clinical support. Finally, we would like to thank all the volunteers who participated in this study.

\section{DISCLOSURE/CONFLICT OF INTEREST}

The authors declare that over the past 3 years JPR and BJS have received compensation for consultancy work from Cambridge Cognition Ltd, who now own the behavioral version of the AGNG.

JPR has received compensation from Cambridge University.

$\mathrm{GH}$ has received compensation from Fundacion Lilly, Spain.

WCD has received compensation from Saint Vincent Catholic Medical Centers, the University of Maryland, Imedex, IntraMed Educational Group, CME Incorporated, Pfizer Inc./Medcon, the Neuroscience Education Institute, the Society of Nuclear Medicine, the American Neuropsychiatric Association, Carroll Hospital, Wisconsin Medical School/Current Medical Direction Inc., the Foundation for Advanced Education in the Sciences, Carilion Health Systems, Roanoke VA, the Medical College of Ohio, Mt. Sinai School of Medicine, Washington University, St Louis University, the Karolinska Institute, Laureate Psychiatric Clinic and Hospital (Tulsa), Assistance Publique, Hopitaux de Paris (sponsored by unrestricted educational grant from Servier), Photosound/Mind Matters (sponsored by unrestricted educational grant from Sanofi-Aventis), the University of California at San Diego, the Neuroscience Center, Zurich, of the University of Zurich, Zurich Switzerland.

BJS has received compensation from Massachusetts General Hospital, the International Conference on Cognitive Dysfunction in Schizophrenia and Mood Disorders, the Medical Research Council Neurosciences \& Mental Health Board, the Science Co-ordination Team for the Foresight Project on Mental Capital and Wellbeing (Office of Science and Innovation, Department of Trade and Industry), and the journal Psychological Medicine.

\section{REFERENCES}

Andrade R (1998). Regulation of membrane excitability in the central nervous system by serotonin receptor subtypes. Ann N Y Acad Sci 861: 190-203.

Bell CJ, Hood SD, Nutt DJ (2005). Acute tryptophan depletion. Part II: clinical effects and implications. Aust $N$ Z J Psychiatry 39: 565-574.

Booij L, Van der Does W, Benkelfat C, Bremner JD, Cowen PJ, Fava $M$ et al (2002). Predictors of mood response to acute tryptophan depletion. A reanalysis. Neuropsychopharmacology 27: 852-861.

Brown JW, Braver TS (2005). Learned predictions of error likelihood in the anterior cingulate cortex. Science 307: 1118-1121. 
Cato MA, Crosson B, Gokcay D, Soltysik D, Wierenga C, Gopinath $\mathrm{K}$ et al (2004). Processing words with emotional connotation: an FMRI study of time course and laterality in rostral frontal and retrosplenial cortices. J Cogn Neurosci 16: 167-177.

Charney DS, Drevets WC (2002). The neurobiological basis of anxiety disorders. In: Davis KL, Charney DS, Coyle JT, Nemeroff CB (eds). Neuropsychopharmacology. The Fifth Generation of Progress. Lippincott, Williams \& Wilkins: Philedelphia. pp 910-930.

Cools R, Blackwell A, Clark L, Menzies L, Cox S, Robbins TW (2005a). Tryptophan depletion disrupts the motivational guidance of goal-directed behavior as a function of trait impulsivity. Neuropsychopharmacology 30: 1362-1373.

Cools R, Calder AJ, Lawrence AD, Clark L, Bullmore E, Robbins TW (2005b). Individual differences in threat sensitivity predict serotonergic modulation of amygdala response to fearful faces. Psychopharmacology (Berl) 180: 670-679.

Deutch AY, Roth RH (1990). The determinants of stress-induced activation of the prefrontal cortical dopamine system. Prog Brain Res 85: 367-402; discussion 402-403.

Drevets WC (2000). Neuroimaging studies of mood disorders. Biol Psychiatry 48: 813-829.

Drevets WC, Bogers W, Raichle ME (2002). Functional anatomical correlates of antidepressant drug treatment assessed using PET measures of regional glucose metabolism. Eur Neuropsychopharmacol 12: 527-544.

Drevets WC, Gautier C, Price JC, Kupfer DJ, Kinahan PE, Grace AA et al (2001). Amphetamine-induced dopamine release in human ventral striatum correlates with euphoria. Biol Psychiatry 49: 81-96.

Drevets WC, Price JC (2005). Neuroimaging and neuropathological studies of mood disorders. In: Licinio J, Wong ML (eds). Biology of Depression: From Novel Insights to Therapeutic Strategies. Wiley-VCH Verlag GmbH \& Co.: Weinheim, Germany. pp 427-466.

Drevets WC, Raichle ME (1992). Neuroanatomical circuits in depression: implications for treatment mechanisms. Psychopharmacol Bull 28: 261-274.

Drevets WC, Videen TO, Price JL, Preskorn SH, Carmichael ST, Raichle ME (1992). A functional anatomical study of unipolar depression. J Neurosci 12: 3628-3641.

Elliott R, Rubinsztein JS, Sahakian BJ, Dolan RJ (2000). Selective attention to emotional stimuli in a verbal go/no-go task: an fMRI study. Neuroreport 11: 1739-1744.

Elliott R, Rubinsztein JS, Sahakian BJ, Dolan RJ (2002). The neural basis of mood-congruent processing biases in depression. Arch Gen Psychiatry 59: 597-604.

Erickson K, Drevets WC, Clark L, Cannon DM, Bain EE, Zarate Jr CA et al (2005). Mood-congruent bias in affective go/no-go performance of unmedicated patients with major depressive disorder. Am J Psychiatry 162: 2171-2173.

Furst P, Pollack L, Graser TA, Godel H, Stehle P (1990). Appraisal of four pre-column derivatization methods for the highperformance liquid chromatographic determination of free amino acids in biological materials. J Chromatogr 499: 557-569.

Hamilton M (1959). The assessment of anxiety states by rating. Br J Med Psychol 32: 50-55.

Hamilton M (1960). A rating scale for depression. J Neurol, Neurosurg Psychiatry 23: 56-62.

Harmer CJ, Mackay CE, Reid CB, Cowen PJ, Goodwin GM (2006). Antidepressant drug treatment modifies the neural processing of nonconscious threat cues. Biol Psychiatry 59: 816-820.

Harmer CJ, Rogers RD, Tunbridge E, Cowen PJ, Goodwin GM (2003). Tryptophan depletion decreases the recognition of fear in female volunteers. Psychopharmacology (Berl) 167: 411-417.

Hollon SD, Kendall PC (1980). Cognitive self-statements in depression: development of an automatic thoughts questionnaire. Cogn Ther Res 4: 383-395.

Howell DC (2002). Statistical Methods for Psychology, 5th edn. Duxbury Press: London.
Inoue T, Tsuchiya K, Koyama T (1994). Regional changes in dopamine and serotonin activation with various intensity of physical and psychological stress in the rat brain. Pharmacol Biochem Behav 49: 911-920.

Jacobs BL, Azmitia EC (1992). Structure and function of the brain serotonin system. Physiol Rev 72: 165-229.

Knutson B, Fong GW, Bennett SM, Adams CM, Hommer D (2003). A region of mesial prefrontal cortex tracks monetarily rewarding outcomes: characterization with rapid event-related fMRI. NeuroImage 18: 263-272.

Kondo H, Saleem KS, Price JL (2005). Differential connections of the perirhinal and parahippocampal cortex with the orbital and medial prefrontal networks in macaque monkeys. J Comp Neurol 493: 479-509.

Kuchinke L, Jacobs AM, Grubich C, Võ ML-H, Conrad M, Herrmann $M$ (2005). Incidental effects of emotional valence in single word processing: an fMRI study. NeuroImage 28: 1022-1032.

Maddock RJ, Garrett AS, Buonocore MH (2003). Posterior cingulate cortex activation by emotional words: fMRI evidence from a valence decision task. Hum Brain Mapp 18: 30-41.

Mai JK, Assheuer J, Paxinos G (2003). Atlas of the Human Brain, 2nd edn. Academic Press: San Diego.

Maxwell E (1992). Family Interview for Genetic Studies (FIGS) A Manual for FIGS. Clinical Neurogenetics Branch, Intramural Research Program, National Institute of Mental Health: Bethesda, MD.

Mayberg HS, Liotti M, Brannan SK, McGinnis S, Mahurin RK, Jerabek PA et al (1999). Reciprocal limbic-cortical function and negative mood: converging PET findings in depression and normal sadness. Am J Psychiatry 156: 675-682.

McNair DM, Lorr M, Droppleman LF (1971). Manual: Profile of Mood States (POMS). Educational \& Industrial Testing Service: San Diego.

Meeter M, Talamini L, Schmitt JA, Riedel WJ (2006). Effects of 5-HT on memory and the hippocampus: model and data. Neuropsychopharmacology 31: 712-720.

Murphy FC, Sahakian BJ, Rubinsztein JS, Michael A, Rogers RD, Robbins TW et al (1999). Emotional bias and inhibitory control processes in mania and depression. Psychol Med 29: 1307-1321.

Murphy FC, Smith KA, Cowen PJ, Robbins TW, Sahakian BJ (2002). The effects of tryptophan depletion on cognitive and affective processing in healthy volunteers. Psychopharmacology (Berl) 163: 42-53.

Neumeister A, Nugent AC, Waldeck T, Geraci M, Schwarz M, Bonne $\mathrm{O}$ et al (2004). Neural and behavioral responses to tryptophan depletion in unmedicated patients with remitted major depressive disorder and controls. Arch Gen Psychiatry 61: 765-773.

Nugent AC, Milham MP, Bain EE, Mah L, Cannon DM, Marrett S et al (2006). Cortical abnormalities in bipolar disorder investigated with MRI and voxel-based morphometry. NeuroImage 30: 485-497.

Ongur D, Ferry AT, Price JL (2003). Architectonic subdivision of the human orbital and medial prefrontal cortex. J Comp Neurol 460: 425-449.

Ongur D, Price JL (2000). The organization of networks within the orbital and medial prefrontal cortex of rats, monkeys and humans. Cereb Cortex 10: 206-219.

Pehek EA, Nocjar C, Roth BL, Byrd TA, Mabrouk OS (2006). Evidence for the preferential involvement of 5-HT2A serotonin receptors in stress- and drug-induced dopamine release in the rat medial prefrontal cortex. Neuropsychopharmacology 31: 265-277.

Peroutka SJ, Schmidt AW, Sleight AJ, Harrington MA (1990). Serotonin receptor 'families' in the central nervous system: an overview. Ann N Y Acad Sci 600: 104-112; discussion 113.

Phillips ML, Drevets WC, Rauch SL, Lane R (2003a). Neurobiology of emotion perception I: the neural basis of normal emotion perception. Biol Psychiatry 54: 504-514. 
Phillips ML, Drevets WC, Rauch SL, Lane R (2003b). Neurobiology of emotion perception II: implications for major psychiatric disorders. Biol Psychiatry 54: 515-528.

Porras G, Di Matteo V, Fracasso C, Lucas G, De Deurwaerdere P, Caccia $S$ et al (2002). 5-HT2A and 5-HT2C/2B receptor subtypes modulate dopamine release induced in vivo by amphetamine and morphine in both the rat nucleus accumbens and striatum. Neuropsychopharmacology 26: 311-324.

Rogers RD, Everitt BJ, Baldacchino A, Blackshaw AJ, Swainson R, Wynne $\mathrm{K}$ et al (1999). Dissociable deficits in the decisionmaking cognition of chronic amphetamine abusers, opiate abusers, patients with focal damage to prefrontal cortex, and tryptophan-depleted normal volunteers: evidence for monoaminergic mechanisms. Neuropsychopharmacology 20: 322-339.

Rogers RD, Tunbridge EM, Bhagwagar Z, Drevets WC, Sahakian BJ, Carter CS (2003). Tryptophan depletion alters the decisionmaking of healthy volunteers through altered processing of reward cues. Neuropsychopharmacology 28: 153-162.

Roiser JP, Blackwell AD, Cools R, Clark L, Rubinsztein DC, Robbins TW et al (2006). Serotonin transporter polymorphism mediates vulnerability to loss of incentive motivation following acute tryptophan depletion. Neuropsychopharmacology 31: 2264-2272.

Saxena PR, Villalon CM (1990). Cardiovascular effects of serotonin agonists and antagonists. J Cardiovasc Pharmacol 15(Suppl 7): S17-S34.

Schatzberg AF, Garlow SJ, Nemeroff CB (2002). Molecular and cellular mechanisms in depression. In: Davis KL, Charney DS, Coyle JT, Nemeroff CB (eds). Neuropsychopharmacology. The Fifth Generation Of Progress. Lippincott, Williams \& Wilkins: Philadelphia. pp 1039-1050.

Schultz W, Tremblay L, Hollerman JR (2003). Changes in behavior-related neuronal activity in the striatum during learning. Trends Neurosci 26: 321-328.
Siegle GJ, Steinhauer SR, Thase ME, Stenger VA, Carter CS (2002). Can't shake that feeling: event-related fMRI assessment of sustained amygdala activity in response to emotional information in depressed individuals. Biol Psychiatry 51: 693-707.

Spielberger CD, Gorsuch RL, Lushene RE (1970). Manual for the State-Trait Anxiety Inventory. Consulting Psychologists Press: Palo Alto, CA.

Spitzer MB, Gibbon M, Williams JBW (2002). Stuctured Clinical Interview for DSM-IV-TR, Research Version, Patient Edition. $(S C I D-I / P)$. Biometrics Research, New York State Biometrics Institute: New York.

Talairach J, Tournoux P (1988). Coplanar Stereotactic Atlas of the Human Brain. Thieme: Stuttgart-New York.

van der Veen FM, Evers EA, Deutz NE, Schmitt JA (2007). Effects of acute tryptophan depletion on mood and facial emotion perception related brain activation and performance in healthy women with and without a family history of depression. Neuropsychopharmacology 32: 216-224.

Varnas K, Halldin C, Hall H (2004). Autoradiographic distribution of serotonin transporters and receptor subtypes in human brain. Hum Brain Mapp 22: 246-260.

Yan QS (2000). Activation of 5-HT2A/2C receptors within the nucleus accumbens increases local dopaminergic transmission. Brain Res Bull 51: 75-81.

Young SN, Smith SE, Pihl RO, Ervin FR (1985). Tryptophan depletion causes a rapid lowering of mood in normal males. Psychopharmacology (Berl) 87: 173-177.

Zink CF, Pagnoni G, Chappelow J, Martin-Skurski M, Berns GS (2006). Human striatal activation reflects degree of stimulus saliency. Neuroimage 29: 977-983.

Zink CF, Pagnoni G, Martin-Skurski ME, Chappelow JC, Berns GS (2004). Human striatal responses to monetary reward depend on saliency. Neuron 42: 509-517. 